Language and Language Teaching Journal http://e-journal.usd.ac.id/index.php/LLT Sanata Dharma University, Yogyakarta, Indonesia

\title{
ERRORS AND CORRECTIVE FEEDBACK IN WRITING: IMPLICATIONS TO OUR CLASSROOM PRACTICES
}

\author{
Maria Corazon Saturnina A. Castro \\ University of the Philippines, Quezon City, The Philippines \\ mcsacastro@gmail.com \\ DOI: doi.org/10.24071/11t.2017.200210
}

received 6 July 2017; revised 30 August 2017; accepted 29 September 2017

\begin{abstract}
Error correction is one of the most contentious and misunderstood issues in both foreign and second language teaching. Despite varying positions on the effectiveness of error correction or the lack of it, corrective feedback remains an institution in the writing classes. Given this context, this action research endeavors to survey prevalent attitudes of teachers and students toward corrective feedback and examine their implications to classroom practices. This paper poses the major problem: How do teachers' perspectives on corrective feedback match the students' views and expectations about error treatment in their writing? Professors of the University of the Philippines who teach composition classes and over a hundred students enrolled in their classes were surveyed. Results showed that there are differing perceptions of teachers and students regarding corrective feedback. These oppositions must be addressed as they have implications to current pedagogical practices which include constructing and establishing appropriate lesson goals, using alternative corrective strategies, teaching grammar points in class even in the tertiary level, and further understanding the learning process.
\end{abstract}

Keywords: writing, errors, corrective feedback, classroom practices, teaching strategies

\section{Introduction}

Academic writing is not easy. It is cognitively complex as it tests the student's ability to use a language and to express ideas in that language. For second language learners, academic writing is more complicated as they go through different stages of acquisition of the different elements of the second language (L2) and make errors reflective of the second language acquisition (SLA) processes. Corder (cited in James, 1998) defines errors as the result of some failure of performance. Dulay, Burt, and Krashen (1982) state that errors are the flawed side of a learner's speech or writing. An error is any deviation from a selected norm of language performance, no matter what the characteristics or causes might be. There have been a number of error taxonomies presented in second language (L2) literature. Corder (1973) classified errors into four categories: omission of some required elements; addition of some unnecessary elements; selection of incorrect element; disordering of elements. James (1998) noted that errors may be interlingua, i.e., mother-tongued influenced. These are 
errors resulting from the learner indulging in a literal translation from L1 to L2. The target language may also cause intralingua errors. The learner may also resort to some communication strategies- based errors such as approximation and circumlocution errors. Lastly, induced errors are errors that result from the language situation rather than the learner' $\mathrm{s}$ incomplete competence of the target language or the interference of the mother language. Corder (1967) argued that making errors is part of second language (L2) developmental stage.

If errors are inevitable and integral part of L2 learning, how would teaching practitioners treat errors specifically in writing. Error correction is one of the most contentious and misunderstood issues in both foreign and second language teaching. Until the 70's, L2 writing was primarily for language practice - that is to say, manipulate grammar forms, learn and use new vocabulary items (Ferris and Hedgecock, 2005). Teachers paid a lot of attention to accuracy and error correction was a major component of writing instruction. However, there was a paradigm shift after this period and composition teachers focused on the process of writing. Discovering ideas, drafting, revising was given importance and students were empowered to make decisions about refining their own work. Composition instruction entered a "period of benign neglect of errors and grammar teaching" (Ferris, 1995). A number of scholars also pointed out the limitations of the process approach. The reality is, as many of us have observed even in our own classes, that students' accuracy does not automatically improve by itself (Eskey, 1983). There is still a need for teacher instruction and intervention. Inevitably, this observation resulted in a renewed interest in error correction and grammar instruction even at the tertiary level.

In the University of the Philippines, despite varying positions on the effectiveness of error correction or the lack of it, corrective feedback remains an institution in the General Education (GE) writing classes. Given this context, this action research endeavors to survey prevalent attitudes of teachers and students toward corrective feedback and examine their implications to classroom practices. This paper poses the major problem: How do teachers' perspectives on corrective feedback match the students' views and expectations about error treatment in their writing? This major inquiry is further broken down into the following subproblems such as what are the dominant positions of teachers regarding corrective feedback? what approaches do teachers adopt to correct errors in the students' writing? do students find value in corrective feedback? what specific corrective feedback do students find helpful in their writing? and in what ways do students find corrective feedback helpful in their writing?

\section{Method}

Faculty members who taught writing classes during the 1st Semester of School year 2016-2017 at the Department of English and Comparative Literature of the University of the Philippines were surveyed. These faculty members ranged from Instructor to Full Professor rank. Their teaching experience ranged from three (3) years to thirty-seven (37) years. All have handled English 1, 10, 30 which are the writing courses in the University. English 1 is Basic College English and it tackles basic grammar, usage, and composition skills in English. 
English 10 is College English and it focuses on the writing and critical reading of forms of academic discourse essential to university work. Lastly, English 30 is English for the professions and it concentrates on principles and the uses of writing in English in the various disciplines/professions. One hundred (100) students enrolled in the three writing classes participated in the survey which was administered between September-November, 2016.

\section{Findings and Discussion}

To determine the dominant positions of teachers regarding corrective feedback, two related questions were asked of them: do you think that errors in writing must be corrected? And do you think that every error must be corrected? If your answer is $\mathrm{NO}$, state your reasons and write down what types of errors must be corrected.

Table 1. Number of respondents: 15 Faculty

\begin{tabular}{|c|c|c|}
\hline Question & yes & No \\
\hline $\begin{array}{l}\text { 1. Do you think that } \\
\text { errors in writing } \\
\text { must be corrected? }\end{array}$ & $100 \%$ & $0 \%$ \\
\hline $\begin{array}{l}\text { 2. Do you think that } \\
\text { every error must be } \\
\text { corrected? }\end{array}$ & $20 \%$ & $80 \%$ \\
\hline
\end{tabular}

The results of the survey show that all the teachers agreed that errors must be corrected; however, majority believe that not every error must be corrected. The reasons for not correcting all errors range from affective concerns to pedagogical/teaching issues. They observed that students get discouraged when they see their papers full of marks. Too many corrections can also prove overwhelming and counterproductive to revision. For the pedagogical issues, not a few shared the idea that students must eventually learn to identify, correct their errors, and rely "on their sense of language." Teachers must point out or correct errors that are glaring and repetitive and this strategy may involve identifying just top three types of errors. The students must be allowed to find and correct their own errors with minimal intervention on the part of the teacher. Some faculty also noted time management issues. Correcting all errors of 25-27 students in one class can be time consuming and may veer the attention away from content. All errors, therefore, can be corrected in stages across several writing sessions. One young faculty highlighted the variety of English that students are familiar with. She argued that "errors that are considered acceptable features of the variety of English that the student is immersed in need not be corrected." This pedagogical position actually calls for not only a more tolerant view of "errors" but, of a more comprehensive understanding of the socio-cultural dynamics involved in the teaching of English. Those who answered that all errors must be corrected pointed out the primary responsibility of the teacher to exhibit a "certain standard of 
English." According to her, "Details matter as many people still judge one's credibility and intelligence based on his/her proficiency in English."

Like the faculty, the students also believed that all errors must be corrected but unlike the faculty, $80 \%$ of the students said that all errors must be corrected (see Table 2). The students strongly believed in the value of error correction and have specific reasons why all errors must be corrected. For most of them, error correction raises the awareness of the students of grammar forms resulting in the improvement in the knowledge of the language structure and of the composition itself. Errors, grammatical or otherwise, can distort the idea/message that students want to convey. The communication of thoughts and the comprehensibility of the composition can be dramatically improved by addressing morphological and syntactic weaknesses. In addition, the students also expressed apprehension that uncorrected errors would have impact on their future. Some of them articulated that "learning the rules of grammar through corrective feedback would be helpful throughout their careers as employers prefer employees who are proficient in the language." While many expressed that corrective feedback is really meant for them to improve their language skills, some argued that error correction is primarily the professor's responsibility and that "withholding correction is equivalent to refusing to teach."

Table 2. Number of respondents: 100 students

\begin{tabular}{|c|c|c|}
\hline Question & Yes & No \\
\hline $\begin{array}{l}\text { 1. Do you think that } \\
\text { errors in writing } \\
\text { must be corrected? }\end{array}$ & $100 \%$ & $0 \%$ \\
\hline $\begin{array}{l}\text { 2. Do you think that } \\
\text { every error must be } \\
\text { corrected? }\end{array}$ & $80 \%$ & $20 \%$ \\
\hline
\end{tabular}

Those who answered that not every error must be corrected share the opinion of most of the faculty that correcting every error can be cognitively and affectively counterproductive. One student wrote that too many corrections can be "disheartening." For most of these students, the teachers must just guide /advise students but allow them to discover and correct their own errors. The students and the faculty were also matched in the belief that only fossilized and repetitive and global errors must be pointed out. Global errors are those that affect the overall sentence organization of a text. They are the ones which are likely to have a marked effect on comprehension (Ellis, 2008). The respondents articulated that they should be allowed to address their own stylistic issues that can be reflected in word choice, sentence structure (e.g. passive vs active; loose vs periodic structures) or even in the variety of English preferred by the student. This argument potentially moves students toward the idea of independence and learning autonomy. Given these results, it is important for teachers to give feedback that will encourage rather than dishearten the students to analyze their 
own errors and self-correct. However, this task is easier said than done. It entails the teacher's recognition of the fact that students possess various levels of English even if they are all labeled L2 learners. The students' level of proficiency will have an impact on how well they can understand and apply the corrective feedback. It may not be effective nor feasible to simply point out without explanation an error (e.g. by merely encircling errors).

To find out what approaches do teachers adopt to correct errors in the students' writing and what specific feedback do students find helpful in their writing, two related questions were asked:

1. For the teachers: In correcting errors, what kind of corrective feedback do you give?

Direct feedback

Indirect Feedback

Both

If your answer is both, which type of feedback do you think is more helpful to the student in revising the error/s and why?

2. For the student: What kind of corrective feedback do you want your teacher to give you?

Direct feedback

Indirect Feedback

Both

If your answer is both, which type of feedback do you think is more helpful to you in revising the error/s and why?

Eighty-six percent of the faculty provide both direct and indirect corrective feedback. Direct feedback means that the instructor provides the correct linguistic form and the students are merely expected to copy the teacher's suggested correction. On the other hand, indirect feedback occurs when the teacher simply indicates that an error has been made and leaves it to the student to correct the error (Ferris, 2011). The faculty, however, noted that indirect feedback is more helpful to students as they are more challenged to process-think, compose, revise. Direct feedback is done only for commonly committed errors (e.g. SV agreement and verb tense). They also expressed the perception that students prefer both types of feedback. This perception acknowledges the fact that learners have different learning and writing strategies, levels of proficiency, and goals in writing. Giving both direct and indirect feedback provides wider issues that 
teachers can focus on. One noted that "too much direct feedback can be overwhelming; while all indirect can be confusing." Both types of feedback allow the teacher to provide a range of comments from grammatical to vocabulary, content, organization, even the cultural context of the composition. Direct feedback works well with the grammar items while indirect feedback is found suitable in addressing issues in style and organization. In effect, simultaneous attention is given to form and content as well as local and global errors. Studies have shown that L2 learners improve on both content and form during revisions. They are aware of their linguistic deficiencies and are motivated to address writing problems that have been pointed out (Hedgecock \& Lefkowitz, 1994).

The students were aware that their teachers provide direct and indirect feedback; however, majority preferred direct feedback. The students also conveyed the notion that students, in general, prefer direct feedback. Convenience is basically the reason for the preference. "The correct answer is given right away" and students know exactly what to improve on. According the some, "solution is given; and time is saved."

Studies in SLA have acknowledged the benefits of direct feedback. Lalande (1982) noted that clear, explicit feedback can actually help students master the structure of language. However, self-editing strategies can be achieved through "guided learning and problem solving." A different scenario was presented by Ferris (2006). Ferris found out that direct feedback led to more correct revision than indirect feedback. Because students find direct feedback easier and faster, positive results may be seen from one draft to another, to the final paper. However, she also found out that throughout the semester, the students who received primarily indirect feedback reduced their error frequency substantially than those who received direct feedback. Lalande (1982) noted that the cumulative effect of indirect feedback resulted in overall accuracy. Needless to say, the goal of the writing instruction influences the type of feedback the teacher opts to provide. It is apparent that the teachers in the study preferred the type of feedback that would lead the students to think for themselves, develop their own editing styles and strategies, and overcome their language deficiencies with minimal intervention.

The mismatch between what type of feedback teachers provide and what students prefer can lead to a dilemma. How can the use of direct feedback not lead to laziness and overdependence on teachers' markings? What circumstances would make direct feedback appropriate? Ferris (2006) noted that there are at least three circumstances in which teachers may consider giving direct feedback: 1) when students are at beginning levels; 2) when errors are untreatable (untreatable errors are idiosyncratic in nature and requires acquired knowledge of the language to self-correct. Examples are idiomatic expressions, word choice); 3) when the teacher wishes to focus the student's attention on particular error patterns. Since the GE students are already in the tertiary level, what the teachers must consider would be the level of proficiency. For students whom the teachers have identified at low-proficiency, direct feedback may be more beneficial until they are deemed able to self-correct. These students are also more likely to commit repetitive errors. Studies in SLA posited that the input of the teacher has 
demonstrated to aid learner's acquisition of the target forms (Ellis et al., 2008). The teacher may opt to prioritize frequent errors and provide direct correction targeting identified weak areas of specific students. Gradually, direct correction can transition to partial indirect correction - that is to say, erroneous part may be pointed out and metalinguistic information can be given instead of the correct form. Later on, grammar instruction, which may involve students identified to commit similar errors or the entire class, can be planned or adopted to address areas of difficulty.

To determine the importance of corrective feedback to the students, they were asked the question: In what way do students find corrective feedback helpful in their writing? It is heartening to know that the students indicated openness and positive attitude toward corrective feedback. For them, corrective feedback raises their language awareness; their critical thinking is also exercised when processing their teacher's comments. Once they become aware of choices available to them, they are encouraged to review and critique their own compositions by looking for ways to refine their lexical choices and check their grammar accuracy. For them, lexical analysis combined with renewed syntactic awareness would impact on the precision and readability of their compositions. Beyond immediate revision concerns, the students also highlighted the importance of corrective feedback in their future workplaces. While it is important for them to produce error-free texts, it is equally important to develop innovative writing techniques and control their academic language for professional uses.

\section{Conclusion}

One implication of the study is that something has to be done regarding the mismatch between the expectations of teachers and students in the type of corrective feedback that teachers should provide. Ultimately, the goal of corrective feedback should be toward learner autonomy. Teachers should explain corrective feedback philosophies and strategies (i.e., which errors to address; how errors will be corrected; when errors will be corrected) so students will be able to manage their expectations and even their anxieties in receiving feedback. Teachers should also set realistic goals. Marking every error is stressful and teachers eventually experience burnout; In addition, corrective feedback is not expected to eliminate all errors. This condition led one teacher to suggest correcting errors across different writing assignments - that is to say, for teachers to do selective correction in various writing activities until all errors have been identified and addressed.

Teachers must also recognize some issues that relate to second language acquisition (SLA). Errors made by students reflect different types and levels of linguistic knowledge. Truscott (1996) argued that different types of errors need varying treatments in terms of error correction. It would be beneficial to both teachers and students if the teachers would make themselves familiar with SLA theories that can support correction strategies. Grammar issues and correction would then be put in perspective.

Teachers must provide a broad range of commenting strategies. They can request more information, address grammar, style, organization. These various 
instructional feedbacks should inform students of the location and nature of their errors while providing encouraging feedback. This strategy engages the students and motivates them to take an active participation in writing instead of simply copying the teacher's correction. In effect, two issues in corrective feedback can be addressed - the affective and the pedagogical.

The survey showed that most of the errors found in students' composition are grammar errors. Grammar correction can be complemented by grammar instructions even in the tertiary level. However, unlike in elementary and High School, supporting grammar instruction must be brief, focused, and based on students' needs as determined by diagnostic tests and other writing assignments. Depending on the teacher's evaluation, grammar instruction can be given to individual students or small groups during conferencing or to the entire class.

Some errors may be too complicated and may not be addressed through written feedback. Conferencing, therefore, may be more effective. The teachers must consider student willingness and ability to understand and cope with conferencing dynamics. As teacher-student relationship adds a layer of stress or awkwardness on the part of the student, teacher-student can be relaxed so teachers can ease the transformation of students from passive to active participants in conferences. In a study by Sheppard (1992), it was noted that students who negotiate meaning in a teacher-student conference are likely to be accurate in their use of language that those who are drawn to repair techniques (e.g., direct feedback).

Some teachers indicated peer evaluation as an alternative mechanism for feedback. Theoretical perspectives in both SLA and writing have acknowledged the benefits of peer evaluation but teachers must caution against actual problems, the most common of which is, the students not knowing what and how to correct. Peer evaluation works well within the context of students who have similar levels of proficiency but the reality in the classroom is, students have varying levels of abilities as writers. Slower students may benefit from the more advanced students. Unprepared students, on the other hand, might find the process of collaborative correction helpful or intimidating. What is important though is for teachers to reevaluate the goals of using peer evaluation in their own classes, the general attitude of students, and the procedure used in peer evaluation.

The results of the study should make teachers re-evaluate their perspectives in corrective feedback. Teachers need to shift their students' focus as well as their own. It is understandable that students want feedback but they should also know that for long term goals, direct feedback may not be as effective as indirect feedback. The teachers, on the hand, must begin to address differing perspectives in providing feedback by arming themselves with pedagogical and theoretical issues in SLA and corrective feedback. This way, they will have a better understanding of language processes and more significantly, of their own teaching.

\section{References}

Corder, S. P. (1981). Error analysis and interlanguage. Oxford: Oxford University Press. 
LLT, e-ISSN 2579-9533, p-ISSN 1410-7201, Vol. 20, No. 2, October 2017

Dulay, H., Burt, M., \& Krashen, S. (1982). Language two. Oxford: Oxford University Press.

Ferris, D.R. (2011). Treatment of errors in second language student writing ( $^{\text {nd }}$ ed.). Ann Arbor, MI: The University of Michigan Press.

Ferris, D.R., \& Hedgecock, J.S. (1998). Teaching ESL compositions: Purpose, process, and practice. Upper Saddle River, NJ: Lawrence Erlbaum Associates.

Hedgecock, J.S., \& Lefkowitz, N. (1994). Feedback on feedback: Assessing learning receptivity in Second language writing. Journal of Second Language Writing, 3, 141-163.

James, C. (1998). Errors and language learning and use: Exploring error analysis. New York: Pearson Longman.

Lalande, J. F. (1982). Reducing composition errors: An experiment. Modern Language Journal, 66, 140-149.

Sheppard, K. (1992). Two feedback types: Do they make a difference? RELC Journal, 23, 103-110.

Truscott, J. (1996). The case against grammar correction in L2 writing classes. Language Learning, 46, 327-369. 